Poels, M., Koster M.P.H., Boeije, H.R., Franx, A., Stel, H.F. Why do women not use preconception care? A systematic review on barriers and facilitators. Obstetrical and Gynecological Survey: 2016, 71(10), 603-612

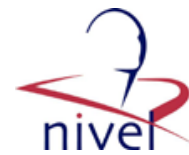

\begin{tabular}{l|l}
$\begin{array}{l}\text { Postprint } \\
\text { Version }\end{array}$ & 1.0 \\
Journal website & https://dx.doi.org/10.1097/OGX.0000000000000360 \\
\hline Pubmed link & $\underline{\text { https://www.ncbi.nlm.nih.gov/pubmed/27770130 }}$ \\
\hline DOI & $10.1097 /$ OGX.0000000000000360
\end{tabular}

This is a NIVEL certified Post Print, more info at http://www.nivel.eu

\title{
Why Do Women Not Use Preconception Care? A Systematic Review On Barriers And Facilitators
}

\author{
Marjolein Poels, MSc, * Maria P. H. Koster, MD, PhD, † Hennie R. BoeiJe, PhD, $\ddagger$ \\ ARIE FrANX, MD, PHD,§ AND HENK F. VAN STEL, PhD \\ *PhD Student and †Assistant Professor, Department of Obstetrics and Gynecology, \\ University Medical Center Utrecht, Utrecht, the Netherlands; \\ ‡ProgramManager, NIVEL, Netherlands Institute for Health Services Research, Utrecht, the \\ Netherlands; \\ SProfessor and Chair, Department of Obstetrics and Gynecology, University Medical Center \\ Utrecht, Utrecht, the Netherlands; and \\ IAssistant Professor, Department of Health Technology Assessment, Julius Center for \\ Health Sciences and Primary Care, University Medical Center Utrecht, Utrecht, the \\ Netherlands
}

Importance: Preconception care (PCC) has the potential to optimize pregnancy outcomes. However, awareness of PCC among the target population is generally limited, and the use of PCC remains low.

Importance: The objective of this studywas to reviewthe literature onwomen's perceptions regarding barriers and facilitators for the use of PCC.

Evidence Acquisition: A systematic search was conducted inMEDLINE, Embase, CINAHL, and PsycINFO for published studies until February 2015. Original qualitative and quantitative peer-reviewed studies from Western countries in English, holding women's perceptions regarding barriers and facilitators for the use of PCC. Data extraction and analysis were performed using NVivo version 10 software. A coding frame was derived from the findings and applied by 2 authors. Thematic analysis was used to identify key topics and themes.

Results: Twenty-one good-quality articles were included, of which 10 qualitative and 11 quantitative studies.

Seven main themes were identified: preconditions, emotions and beliefs, perceived need, knowledge and experience, social structure, accessibility, and provider characteristics. "Not (fully) planning pregnancy”, "perceived absence of risks", "lack of awareness", and "pregnancy experiences" were the most frequently identified barriers and "believing in the benefits" and "availability of PCC” the most frequently identified facilitators for PCC use.

Conclusions and Relevance: Women perceive more barriers than facilitators related to PCC uptake, which explains why the use of PCC remains low. Our results provide a starting point to refocus interventions and strategies, aiming on 
Poels, M., Koster M.P.H., Boeije, H.R., Franx, A., Stel, H.F. Why do women not use preconception care? A systematic review on barriers and facilitators. Obstetrical and Gynecological Survey: 2016, 71(10), 603-612

enlarging the awareness, perceived importance, and accessibility of PCC to improve its uptake.

Target Audience: Obstetricians and gynecologists, family physicians.

Learning Objectives: After completing this activity, the learner should be better able to (1) appraise the recent literature on barriers and facilitators that affect the uptake rates of preconception care; (2) discuss which perceptions women hold regarding the use of preconception care; and (3) take these factors into account while designing preconception care interventions and strategies.

Preconception care (PCC) is an approach to optimize pregnancy outcomes. Antenatal care often starts too late to prevent serious maternal and child health problems, as the first gestational weeks are of utmost importance for embryonic growth and development.1 Preconception care focuses on the period before conception, providing a preventive window of opportunity to timely alter or eliminate risk factors for adverse pregnancy outcomes.

2,3 The United States Centers for Disease Control defines PCC as "a set of interventions that aim to identify and modify biomedical, behavioral and social risks to a woman's health or pregnancy outcome through prevention and management”.2 The key components of PCC include risk assessment, health promotion, and medical and psychosocial interventions.4 Individual PCC counseling may encompass information about lifestyle, obstetrical history, hereditary diseases, immunization, and medication use.5 The attention for PCC has grown substantially over the past decades and national guidelines and recommendations have been developed in many western countries.2,6,7 Although PCC is increasingly being offered, awareness of PCC among the target population is generally limited and the use of PCC remains low.8 Research indicates that almost all couples planning pregnancy have at least one risk factor for adverse pregnancy outcomes, and most of these risk factors continue to be prevalent during pregnancy.9,10 Preconception care has demonstrated to improve knowledge and change risk behaviors to optimize future pregnancy outcomes and future health.11-13 Yet, the percentage of couples seeking or receiving PCC is disappointing. In the United States, the Pregnancy Risk Assessment Monitoring System was used to analyze data from 2004 to 2010 from a large sample of women. Overall, only 31\% of women reported receiving PCC or consulting a health care provider before conception to prepare for a healthy pregnancy.

Moreover, women with a high risk for adverse pregnancy outcomes were less likely to have received PCC.14 These findings are consistent with a crosssectional survey study among pregnant women in the United Kingdom, in which only $27 \%$ of women visited a health professional for advice about getting pregnant.

15 Despite several attempts to improve the uptake of PCC through tailored interventions and preconception care clinics, it is not clear why women remain hesitant to seek and receive PCC.

In this study, we aimed to systematically review the current literature on factors underlying the differences in PCC uptake. In 2002, Korenbrot et al16 conducted the first systematic review on preconception care, focusing on evidence for its effectiveness. In 2011, Delissaint andMcKyer17 performed another systematic review on factors relating to preconception health status and health behaviors. A critical finding in that review was that knowledge and awareness do not lead to 
Poels, M., Koster M.P.H., Boeije, H.R., Franx, A., Stel, H.F. Why do women not use preconception care? A systematic review on barriers and facilitators. Obstetrical and Gynecological Survey: 2016, 71(10), 603-612

preconception health practices.17 Our study builds on their previous work by examining what factors women perceive as barriers and facilitators for the use of preconception care.

\section{METHODS}

\section{Search Strategy}

Four databases (MEDLINE, Embase, CINAHL, and PsycINFO) were searched for English peer-reviewed literature up to February 2015. A search syntax was used with a combination of 3 groups of keywords: (1) terms defining the domain "preconception care"; (2) terms identifying determinants, such as "factors", "facilitators", and "barriers"; and (3) terms related to "use”, such as "uptake”, "receipt” and "attendance".

The complete search syntax is listed in Table 1.

\section{[TABLE 1]}

\section{Selection Strategy}

Two authors (M.P. and H.vS.) were responsible for article selection. Both authors simultaneously screened the first 150 titles and abstracts. Discrepancies for inclusion or exclusion were discussed, and the selection strategy was further specified. One author (M.P.) screened all remaining titles and abstracts. In case of doubt, again, both authors discussed the selection. Subsequently, both authors screened all full-text articles.

The references of included studies were checked for other eligible articles for this review (snowball method).

The following inclusion criteria were applied: original and peer-reviewed research in English; research from Western countries; qualitative and quantitative research; research in which participants were women with a pregnancy wish, pregnant women, women with past pregnancy, or women in the reproductive age (15-44 years); studies describing the use of preconception care; studies describing women's perceived barriers and facilitators for the use of PCC. Studies evaluating or describing the effect of a PCC intervention were excluded. In addition, studies focusing on a single part of preconception care (eg, folic acid supplementation or carrier screening) were excluded, as well as studies from which only a conference abstract was available.

\section{Data Extraction and Analysis}

We included both quantitative and qualitative studies. The quality of included articles was assessed by 2 authors (M.P. and H.vS.), using the Critical Appraisal Skills Program checklist for qualitative articles and the Health Evidence BulletinsWales checklist for quantitative articles.18,19 There is little empirical evidence on which criteria exclusion decisions should be based in mixed studies reviews. 20 Therefore, we decided to report on the quality of each article rather than to exclude articles.Moreover, topics present in at least 2 studies were automatically included in the results. Topics present in only one article were included when the study was judged to be of sufficient quality. Data extraction and analysis was performed using the NVivo version 10 software.21 Thematic analysis was used to identify key topics and themes.22 One author (M.P.) developed an initial coding frame by reading and 
Poels, M., Koster M.P.H., Boeije, H.R., Franx, A., Stel, H.F. Why do women not use preconception care? A systematic review on barriers and facilitators. Obstetrical and Gynecological Survey: 2016, 71(10), 603-612

rereading the extracted findings and subsequently coded the results into topics and themes. Emergent topics were added when results did not fit the coding frame. Extraction and coding was verified by a second author (H.vS.) and discrepancies were discussed until consensus was attained.

\section{RESULTS}

\section{Studies Included}

The literature search generated a total of 2260 results.

Seventeen publications met all inclusion criteria, and the snowball method added 4 more articles (Fig. 1). In total, 21 articles were included for analysis of which 10 with a qualitative design and 11 with a quantitative design. All studies were carried out in Western countries. In 10 of the articles, a specific target group was sampled: women with pregestational diabetes, infertility patients, African American women and Mexican American women.

The characteristics of the included studies are displayed in Table 2.

\section{[FIGURE 1]}

\section{[TABLE 2]}

\section{Quality of Reviewed}

Articles Most studies met the criteria from the quality appraisal checklists. The checklist for qualitative articles contained one item, that is, the adequate consideration of the relationship between the researcher and study participants, which was met in only one study.33 The other studies did not provide sufficient information on this matter. The method of analysis was not described in 2 quantitative studies and 1 qualitative study.27,29,33 The 2 quantitative studies only used descriptive analyses and no statistical tests to report on their results.27,29 Therefore, not meeting this criterion was considered of minor influence on the quality of these articles. The qualitative study used the participatory research process and did elaborate on the application of this method.

However, the authors did not describe how they further analyzed the retrieved "webs of ideas" but did present participant quotations to support authors' interpretations. 33 Therefore, we decided to use the results under the condition that topics had to be present in at least one other article. Only one quantitative study explicitly considered possible confounding and bias, which may be due to the descriptive character of the articles.26 Three other studies did report on moderator variables or used a multiple regression model to investigate associations between variables.24,30,36We could not retrieve whether ethics were considered in all studies, as 11 of the 21 articles did not report on ethics. Either comprehensive description on obtaining informed consent of participants or institutional review board approval was lacking in these studies.5,23,27,28,31-33,36-38,40 Nine studies met all the criteria from the quality appraisal checklists.8,24-26,30,34,35,39,41 Yet, the overall quality of all included studies was good and adequately reported.

\section{Synthesis of the Findings}

Seven major themes were derived from thematic analysis: preconditions, emotions and beliefs, perceived need, knowledge and experience, social structure, 
Poels, M., Koster M.P.H., Boeije, H.R., Franx, A., Stel, H.F. Why do women not use preconception care? A systematic review on barriers and facilitators. Obstetrical and Gynecological Survey: 2016, 71(10), 603-612

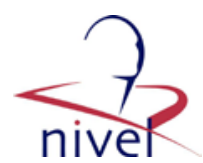

accessibility, and provider characteristics. Table 3 provides an overview of themes and topics in the included studies, classified into barriers (-) and facilitators (+) for the use of preconception care. More barriers than facilitators were identified in the included studies.

The most frequently identified barriers were "lack of awareness", "perceived absence of risks”, "pregnancy experiences”, and "not (fully) planning pregnancy".

The most frequently identified facilitators were: "believing in the benefits" and "availability of PCC”. A description of the findings is given below.

Theme 1: Preconditions

We identified interest as one of the facilitators to engage in PCC. Six included studies reported that most women are interested in PCC, with percentages ranging from $54 \%$ to $86 \% .24,26-29,39,41$ Women should know about the existence of PCC to decide on using PCC, therefore lack of awareness was identified as a barrier for the use of PCC. Eight studies stipulate lack of awareness and unfamiliarity with the concept of PCC.23,25,31-33,35,37,41 Charron-Prochownik et al. performed a study among adolescent women with diabetes.

One of their most significant findings was the strong association $(\mathrm{P} \leq 0.01)$ between initial awareness of PCC and seeking PCC.24 However, 65\% of the respondents in this study stated they never heard of PCC.25 Other studies report that the idea of PCC is foreign to many women, feels abstract, or that the term "preconception care" is too clinical and puts women off.23,35,37 Despite the possibilities of birth control, many pregnancies in Western countries remain unplanned.Not (fully) planning pregnancy was identified as an important barrier for attending PCC, as mentioned in 8 of the included articles.23,27,28,32,34,37,38,41 Illustratively, de Jong-Potjer et al and Elsinga et al found that the major reason (54\%-67\%) for refusing PCC was that women had no wish for (another) pregnancy. 27,28 Several studies describe the phase between pregnancy planning and actual conception to be indistinct: women do not always make a strategic decision to conceive, convince themselves they are sterile, or conceive sooner than expected.23,32,37,38

\section{[TABLE 3]}

\section{Theme 2: Emotions and Beliefs}

The wish for secrecy is mentioned in 2 articles as a barrier for PCC use.37,38 Many women prefer to keep their pregnancy plans intimate between them and their partners, which affects their willingness to tell others, including health professionals.37,38 Moreover, women wish for normality, as they feel that the process of getting pregnant should be surrounded by "natural" and "romantic" values and should not become artificial.38 Especially women with pregestational diabetes, who already are in the medical realm, wish to have a normal and positive experience of conception and pregnancy, which could be endangered by too much monitoring following PCC.32 Five studies reported feelings of anxiety and fears, which could interfere with the use of PCC. These include personal fears, such as fear for disappointment, the unknown, and blood withdrawal.32,33,36 Moreover, women experience fears in relation to health care providers, such as fear to ask questions; fear for embarrassment; fear of being labeled, judged, or lectured; and fear that confidential information might be passed on to relatives.33,34,37 We identified believing in the benefits as one of the most imperative facilitators for the uptake of PCC, as it was mentioned in 10 included studies.5,8,24,26,30,32,33,35,37,38 
Poels, M., Koster M.P.H., Boeije, H.R., Franx, A., Stel, H.F. Why do women not use preconception care? A systematic review on barriers and facilitators. Obstetrical and Gynecological Survey: 2016, 71(10), 603-612

Although perceived lack of control over birth outcomes could be an issue, 7 studies report that optimizing the health of mother and child is an important motive for women to engage in PCC.8,24,26,30,32,33,35 In addition, 3 studies report that the prospect of being better informed by health providers also contributes to the belief that PCC is beneficial.5,37,38

Theme 3: Perceived Need

The perceived relevance and importance of PCC was predominantly identified as a barrier for PCC uptake in this review. Yet, there was lack of consensus in the literature as the percentages of women who regarded PCC to be important fluctuated from less than $40 \%$ to $99 \% .29,31,36,39,40$ A possible explanation for these contradictory findings provided by the literature is that women do not regard PCC as relevant to themselves but do consider PCC useful for other women.5,32,37,38 Six studies report on this perceived absence of risks and perceived healthy lifestyle among women, which minimized their need of PCC.5,8,23,33,37,38 Illustratively, in the study by van der Zee et al., women reported to have conducted their own risk analysis and concluded they were "safe" or could handle the risk.38 This perception generally changes when women become pregnant, as risks then become relevant and seeking care is recognized as a necessary subsequent step.8,37 Women tend to perceive conception as a normal event that most women go through, and they associate seeing a health care provider with health problems and acute care.8,23 Therefore, medicalization of conception was identified as an inhibiting factor for PCC use, as women do not perceive a need for medical attention before conception and wish for lessmedical input.8,23,32 By contrast, in case of fertility concerns, PCC is generally considered relevant and appropriate, although Murphy et al. found that both realistic and perceived fertility concerns could also act as an impeding factor for PCC out of fear for negative advice.5,23,32,37,38

Theme 4: Knowledge and Experience

Perceived sufficient knowledge constitutes an important barrier in PCC attendance, as this factor was reported in 5 studies.5,8,28,38,41 In the studies by van der Zee et al. and Mazza and Chapman, women reported they had already found the relevant information in books, on the Internet, or from friends and family.8,38 Eight studies mentioned past pregnancy experiences as an impeding factor for PCC use as well, as women feel they are experienced mothers, already knowing about PCC issues.5,8,32,36-38,40,41 There are mixed messages in the literature regarding experience with poor pregnancy outcomes, as one study found that this factor contributed to PCC use, whereas 2 other studies found opposite results.23,32,36 Theme 5: Social Structure

Four articles reported social support as a facilitator for PCC use.30,33,35,36 Although nonsignificant, in the studies by Temel et al. and Janz et al., most women reported their partner's opinion to be very important.30,36 By contrast, social pressure could interfere with women's willingness to use PCC.32,36-38 An important reason to keep secrecy is that women do not want to create expectations they will not be able to meet and do not want other people to involve or inquire about their pregnancy plans.32,38 Apart from this, religion might also inhibit PCC attendance, as some communities may sanction “conception” only in marriage.36,37 Theme 6: Accessibility The accessibility of preconception care has major influence on its uptake, as difficulty accessing PCC makes it more difficult to use PCC services. Logistical 
concerns, such as living in rural areas and travel issues, make PCC less accessible.8,32,41 Three studies indicate that lack of adequate finances impedes on PCC uptake.8,32,35 However, in one study performed in the UK, women did not perceive money as inhibiting because health care is free in this country.34 Another barrier reported by 4 studies is that women find it difficult to commit their time and effort to PCC.32,33,36,41 This seems especially the case when other commitments compound women's demands, such as taking care of their other children.33,37 We found that the way in which PCC is offered within the health care system, either demand or supply driven, can make a substantial difference for the uptake of PCC. The results of 7 studies suggest that provider encouragement and the active offer of PCC facilitates uptake.8,27,28,30,35,37,40 However, 5 studies show that in daily practice, women are mostly not being offered PCC by health care providers and information is not as readily available.8,29,33-35 Illustratively, Frey and Files29 report that only $39 \%$ of their respondents could ever recall their physician discussing preconception health. Moreover, the opportunistic offer of PCC during general practice may not always be appreciated.32,40 Wallace and Hurwitz40 found that acceptability was substantially lower the less closely the original visit related to pregnancy. Discussing PCC is perceived more appropriate during obstetric/gynecology appointments or while consulting the general practice for contraception or Papanicolaou tests.35,40

Theme 7: Provider Characteristics

Preconception care counseling can be delivered by several health care providers, such as general practitioners, practice nurses, midwifes, and gynecologists.

Some specific characteristics of these providers matter for women in their decision to use PCC. An example is that some women prefer to speak with female providers. 34,37 Four studies report that positive provider attitudes contribute to PCC use, such as professional support, reassurance, encouragement, respect, trust, and confidentiality.30,33,37,38 By contrast, negative provider attitudes were mentioned as barriers for PCC use in 2 studies and concerned perceptions of providers being nonreliable, judging, stereotyping, controlling, directive, restrictive, authoritative, or unsupportive of women's needs.34,37 Moreover, 3 studies reported on communication issues with providers, which we identified as barriers for PCC use.32,34,37 Previous negative experiences with health services was mentioned as a reason for nonattending PCC in 3 studies, whereas previous positive experiences with health services and being formerly involved with PCC were factors that contribute to the use of PCC.8,32-34 One study found that women were generally positive about the prospect of greater PCC owing to continuity of positive provider relationships.37 Correspondingly, not having such an ongoing provider relationship was suggested to be a barrier PCC uptake.8,34

\section{DISCUSSION}

To the best of our knowledge, this is the first systematic review of studies on women's perceptions of barriers and facilitators for the use of preconception care. The aim of the review was to identify factors that underlie the differences in PCC uptake. Thematic analysis distinguished 7 themes that are important for women in their consideration to use PCC: preconditions, emotions and beliefs, perceived need, experience, social structure, accessibility, and provider characteristics. 
These findings are rigorous, as we included 21 goodquality articles, both qualitative and quantitative studies, and attained data-saturation during analysis.

Our findings indicate that factors women perceive as relevant for PCC uptake are predominantly barriers, which explains why the use of PCC remains low. Strikingly, almost all identified barriers and facilitators relate to the same topics and themes. For example, already having children was identified a barrier, whereas not having children was identified a facilitator for PCC uptake.

This indicates that our dichotomous categorization into barriers and facilitators in reality is more a continuum, as womenmight shift their perceptions depending on time and context. Furthermore, the identified factors interrelate, which suggests that deciding on the use of PCC is a subtle process, determined by the presence of preconditions, women's beliefs, perceptions, and experiences, given the availability and context in which PCC is provided.

The Andersen Behavioral Model of Health Services Use can be applied to reflect on the themes and topics identified by this systematic review. This model supposes that health care use is a function of 3 determinants: predisposing characteristics (demographic, social, and health belief factors), enabling resources (health system and organizational characteristics, financial and personal factors) and need (perceived and evaluated need).42 Interestingly, most of both barriers and facilitators identified in this review correspond with Andersen's category of predisposing characteristics. This suggests that most factors related to PCC use have limited amenability to change, as they are fixed within the intrapersonal level. The barriers for PCC use most frequently identified in this review were lack of awareness, perceived absence of risks, pregnancy experiences, and not (fully) planning pregnancy. The most frequently identified facilitators were believing in the benefits and availability of PCC. Of these factors, availability of PCC was reported in the included studies to be both a barrier and facilitator factor. Given this, and the fact that this factor is an enabling resource on the organizational level, we single out availability of PCC as the factor most inclined to change by interventions and strategies.

Our findings indicate that perceived absence of risks is one of the most important barriers for PCC use, although evidence shows that almost all couples planning for pregnancy have at least one risk factor for adverse pregnancy outcomes.9 Moreover, several studies indicate that levels of knowledge regarding preconception health are high among women planning for pregnancy.

11,26,29,39,43 Yet, evidence suggests that whereas PCC is effective to change risky health behaviors, having knowledge alone is not enough.11-13,43 Therefore, an increase in the awareness and perceived importance of PCC is desirable. We recommend developing communication and marketing strategies to increase women's awareness that PCC is important to all couples planning pregnancy. Our findings suggest that promotional messages should focus on highlighting possible risks and emphasizing on the benefits associated with PCC, which was indicated as the most important motivator for women to engage in PCC.

However, marketing strategies will not reach all women, as many pregnancies in Western countries remain unplanned.44 In the US, 51\% of the pregnancies are unintended.45 In the UK, these percentages are lower; approximately $16 \%$ of pregnancies are unplanned and approximately $29 \%$ is ambivalent. 46 This review shows that the intention to become pregnant is indeed more a continuum between 
planned and unplanned, which is supported by other studies.47-50 To not miss women who are not (fully) planning pregnancy, it is widely recommended for providers to focus on all women of childbearing age by offering PCC opportunistically during other health encounters.1-3,51 However, our findings indicate that to date, the integration of PCC with primary health care is far from routine.

Moreover, we found that although actively offering PCC has the potential to motivate women, it may not always be appreciated. Therefore, we recommend to enlarge the availability of PCC by investing in other means of delivery, such as walkin-hours, group sessions, and online consultation. A recent systematic review indicates there is no consensus on how PCC should best be delivered owing to heterogeneity of risk factors, health systems, and strategies.52 Moreover, other studies support our finding that practical constraints and provider characteristics also play an important role in the accessibility of PCC services, such as costs, distance, time and effort, trust, the quality of provider relationships, and previous health services experiences.53-58 Therefore, we recommend to design interventions with specific attention to local situations by diminishing possible logistical and financial barriers and enlarging the offer of PCC. From this perspective, we consider it useful to introduce core preconception wellness measures at the initiation of prenatal care, including pregnancy intention and access to care, as advocated by Frayne et al59 in a recent publication. These health care system measures allow for comparison of the aforementioned regional differences in PCC practice and monitor improvements over time.

\section{Strengths and Limitations}

A strength of this review lies in the extensive search strategy, using 4 databases from different fields of medical health care and social sciences. Moreover, there was good representation of the main themes in most of the included studies, and all topics were present in at least 2 studies and saturation was achieved.

We carried out a mixed studies review by including both quantitative and qualitative articles. The strength of this approach is that it allows for more extensive and indepth understanding. The use of thematic analysis allowed us to identify key topics and themes. Yet, combining qualitative and quantitative results might be challenging, as interpretation and generalization go across different designs and data collection methods.

Therefore, 2 authors contributed to data analysis, which enlarged rigor. Moreover, almost all qualitative studies included participant quotations to support authors' interpretations, which enhanced analysis. The degree to which quantitative and qualitative results could be integrated was also high. All themes and almost all topics were present in both quantitative and qualitative research (Table 3). One article did not entirely meet the criteria of the checklist used for quality appraisal.33 However, the results did contribute to our data, as it supported our findings for 10 topics in 6 themes. As these topics were present in other studies as well, the contribution was considered supportive rather than decisive.

Ten of the 21 included articles concerned specific populations, with an overrepresentation of women with diabetes mellitus. These women might have different perceptions compared to the general population, as they have higher risks for adverse pregnancy outcomes and have regular health encounters. Another limitation was that we only included studies from Western countries. 
Our rationale was that experiences from women in non-Western and Western countries are incomparable owing to differences in health care systems, living standards, and health issues. However, we found that these differences also exist between Western countries, as the affordability and availability of PCC closely relates to the organization of primary care and billing and reimbursement options within the health insurance system.1,60 Although topics regarding the accessibility of PCC were presented by studies conducted in multiple countries (USA, UK, the Netherlands, Ireland, and Australia), the generalizability of our findings is limited, as perceptions might vary between countries.8,27-30,32-37,40,41 Therefore, it is recommended to carefully account for the local situation while designing interventions and to introduce preconception baseline measures to allow for monitoring and comparison between regions.

\section{CONCLUSIONS}

This review illustrates that deciding on the use of PCC is a subtle process, determined by the presence of preconditions, women's beliefs, perceptions, and experiences, given the availability and context in which PCC is provided.We are confident that our findings are rigorous, as they are supported by 21 good-quality studies and saturation of both themes and topics was achieved.

Our results show that PCC misses its potential by the current way in which it is offered, as many pregnancies remain unplanned and couples tend to keep their pregnancy wish secret. Thus, it is recommended to enlarge the availability of PCC by investing in other means of delivery while paying specific attention to local situations and subpopulations. Moreover, we recommend to enlarge the awareness and perceived importance of PCC by means of promotional messages, highlighting possible risks and emphasizing on the benefits associated with PCC. Our results contribute to the literature by providing a starting point to refocus interventions and strategies aimed at improving PCC uptake by taking into account factors that women perceive as barriers and facilitators. We urge to apply these recommendations to both current and future policy in order for PCC to reach its potential. A paradigm shift is needed for PCC to become as self-evident as prenatal care and to improve the health of future generations.

ACKNOWLEDGMENTS Funding for this study was provided by the Netherlands Organization for Health Research and Development (ZonMw), which had no role in the research or article (grant no. 209040005).

\section{REFERENCES}

1. AtrashHK, Johnson $\mathrm{K}, \mathrm{AdamsM}$, et al. Preconception care for improving perinatal outcomes: the time to act. Matern Child Health J. 2006;10:S3-S11.

2. Johnson K, Posner SF, Biermann J, et al. Recommendations to improve preconception health and health care-United States: a report of the CDC/ATSDR Preconception Care Work Group and the Select Panel on Preconception Care. MMWR Recomm Rep. 2006;55:1-23.

3. MoosMK, Dunlop AL, Jack BW, et al. Healthier women, healthier reproductive outcomes: recommendations for the routine care of all women of reproductive age. Am J Obstet Gynecol. 2008; 199(6 Suppl 2):S280-S289.

4. LuMC. Recommendations for preconception care. Am FamPhysician. 2007;76(3):397-400.

5. Hosli EJ, Elsinga J, Buitendijk SE, et al.Women's motives for not participating in preconception counseling: qualitative study. 
Poels, M., Koster M.P.H., Boeije, H.R., Franx, A., Stel, H.F. Why do women not use preconception care? A systematic review on barriers and facilitators. Obstetrical and Gynecological Survey: 2016, 71(10), 603-612

Community Genet. 2008;11:166-170.

6. Boulet SL, Parker C, AtrashH. Preconception care in international settings. Matern Child

Health J. 2006;10:S29-S35.

7. Health Council of the Netherlands. Preconception Care: A Good Beginning. Health Council of the Netherlands 2007. Available at: https://www.gezondheidsraad.nl/sites/default/files/200719E.pdf.

Accessed June 15, 2015.

8. Mazza D, Chapman A. Improving the uptake of preconception care and periconceptional folate supplementation: what do women think? BMC Public Health. 2010;10:786.

9. van der Pal-de Bruin KM, le Cessie S, Elsinga J, et al. Preconception counselling in primary care: prevalence of risk factors among couples contemplating pregnancy. Paediatr Perinat Epidemiol.

2008;22:280-287.

10. Anderson JE, Ebrahim S, Floyd L, et al. Prevalence of risk factors for adverse pregnancy outcomes during pregnancy and the preconception period-United States, 2002-2004.

Matern Child Health J. 2006;10:S101-S106.

11. Elsinga J, de Jong-Potjer LC, van der Pal-de Bruin KM, et al. The effect of preconception counselling on lifestyle and other behaviour before and during pregnancy. Womens Health Issues. 2008; 18:S117-S125.

12. Hammiche F, Laven JS, van Mil N, et al. Tailored preconceptional dietary and lifestyle counselling in a tertiary outpatient clinic in The Netherlands. Hum Reprod. 2011;26:24322441.

13. Williams L, Zapata LB, D'Angelo DV, et al. Associations between preconception counseling and maternal behaviors before and during pregnancy. Matern Child Health $\mathrm{J}$. 2012;16:1854-1861.

14. Oza-Frank R, Gilson E, Keim SA, et al. Trends and factors associated with self-reported receipt of preconception care: PRAMS, 2004-2010. Birth. 2014;41:367-373.

15. Stephenson J, Patel D, Barrett G, et al. How do women prepare for pregnancy? Preconception experiences of women attending antenatal services and views of health professionals. PLoS One.

2014;9:e103085.

16. Korenbrot CC, Steinberg A, Bender C, et al. Preconception care: a systematic review. Matern Child Health J. 2002;6(2):75-88.

17. Delissaint $D, M c K y e r$ EL. A systematic review of factors utilized in preconception health behavior research. Health Educ Behav.

2011;38:603-616.

18. Critical Appraisal Skills Programme. 10 questions to help you make sense of qualitative research. Critical Appraisal Skills Programme.

Available at: http://www.casp-uk.net/\#!casp-toolschecklists/ c18f8. Accessed June 1, 2015.

19. Health Evidence Bulletin-Wales. Questions to assist with the critical appraisal of an observational study e.g. cohort, casecontrol, cross-sectional. Available at: http://hebw.cf.ac.uk/ projectmethod/appendix8.htm. Accessed July 1, 2015.

20. Thomas J, Harden A.Methods for the thematic synthesis of qualitative research in systematic reviews. BMC Med Res Methodol.

2008;8:1-10.

21. QSR International Pty Ltd. NVivo qualitative data analysis software.

Version 10, 2012.

22. Braun V, Clark V. Using thematic analysis in psychology. Qual Res Psychol. 2006;3:77101.

23. Canady RB, Tiedje LB, Lauber C. Preconception care \& pregnancy planning: voices of African American women. MCN Am J Matern Child Nurs. 2008;33(2):90-97.

24. Charron-Prochownik D, Sereika SM, Becker D, et al. Reproductive health beliefs and behaviors in teens with diabetes: application of the Expanded Health Belief Model. Pediatr Diabetes.

2001;2:30-39.

25. Charron-Prochownik D, Sereika SM, Wang SL, et al. Reproductive health and preconception counseling awareness in adolescents with diabetes: what they don't know can hurt them. 
Poels, M., Koster M.P.H., Boeije, H.R., Franx, A., Stel, H.F. Why do women not use preconception care? A systematic review on barriers and facilitators. Obstetrical and Gynecological Survey: 2016, 71(10), 603-612

Diabetes Educ. 2006;32(2):235-242.

26. Coonrod DV, Bruce NC, Malcolm TD, et al. Knowledge and attitudes regarding preconception care in a predominantly lowincome Mexican American population. Am J Obstet Gynecol.

2009;200:686.e1-686.e7.

27. de Jong-Potjer LC, de Bock GH, Zaadstra BM, et al. Women's interest in GP-initiated pre-conception counselling in The Netherlands.

Fam Pract. 2003;20:142-146.

28. Elsinga J, van der Pal-de Bruin KM, le Sessie S, et al. Preconception counselling initiated by general practitioners in the Netherlands: reaching couples contemplating pregnancy [ISRCTN53942912].

BMC Fam Pract. 2006; 7:41.

29. Frey KA, Files JA. Preconception healthcare: what women know and believe. Matern Child Health J. 2006;10:S73-S77.

30. Janz NK, Herman WH, Becker MP, et al. Diabetes and pregnancy.

Factors associated with seeking pre-conception care.

Diabetes Care. 1995;18:157-165.

31. Mitchell EW, Levis DM, Prue CE. Preconception health: awareness, planning, and communication among a sample of US men and women. Matern Child Health J. 2012;16:31-39.

32. Murphy HR, Temple RC, Ball VE, et al. Personal experiences of women with diabetes who do not attend pre-pregnancy care.

Diabet Med. 2010;27:92-100.

33. O'Higgins S, McGuire BE, Mustafa E, et al. Barriers and facilitators to attending prepregnancy care services: the ATLANTICDIP experience. Diabet Med. 2014;31:366-374.

34. SpenceM, Alderdice FA, Harper R, et al. An exploration of knowledge and attitudes related to pre-pregnancy care in women with diabetes. Diabet Med. 2010;27:1385-1391.

35. Squiers L, Mitchell EW, Levis DM, et al. Consumers' perceptions of preconception health. AmJ Health Promot. 2013;27:S10-S19.

36. Temel S, Birnie E, Sonneveld HM, et al. Determinants of the intention of preconception care use: lessons from a multi-ethnic urban population in the Netherlands. Int J Public Health. 2013; 58(2):295-304.

37. Tuomainen H, Cross-Bardell L, Bhoday M, et al. Opportunities and challenges for enhancing preconception health in primary care: qualitative study with women from ethnically diverse communities.

BMJ Open. 2013;3:e002977.

38. van der Zee B, de Beaufort ID, Steegers EA, et al. Perceptions of preconception counselling among women planning a pregnancy: a qualitative study. Fam Pract. 2013;30(3):341-346.

39. Vause TD, Jones L, Evans M, et al. Pre-conception health awareness in infertility patients. J Obstet Gynaecol Can. 2009; 31(8):717-720.

40. Wallace M, Hurwitz B. Preconception care: who needs it, who wants it, and how should it be provided? $\mathrm{Br} \mathrm{J}$ Gen Pract.

1998;48(427):963-966.

41. Zhu H,GrahamD, TehRW, et al.Utilisation of preconception care in women with pregestational diabetes inWestern Australia. Aust N Z J Obstet Gynaecol. 2012;52:593596.

42. Andersen RM. Revisiting the behavioral model and access to medical care: does it matter? J HealthSocBehav. 1995;36:1-10.

43. Harelick L, Viola D, Tahara D. Preconception health of low socioeconomic status women: assessing knowledge and behaviors.

Womens Health Issues. 2011;21:272-276.

44. Sedgh G, Singh S, Hussain R. Intended and unintended pregnancies worldwide in 2012 and recent trends. Stud Fam Plann.

2014;45:301-314.

45. Finer LB, Zolna MR. Shifts in intended and unintended pregnancies in the United States, 2001-2008. Am J Public Health.

2014;104:S43-S48. 
Poels, M., Koster M.P.H., Boeije, H.R., Franx, A., Stel, H.F. Why do women not use preconception care? A systematic review on barriers and facilitators. Obstetrical and Gynecological Survey: 2016, 71(10), 603-612

46. Wellings $\mathrm{K}$, Jones KG, Mercer $\mathrm{CH}$, et al. The prevalence of unplanned pregnancy and associated factors in Britain: findings from the third National Survey of Sexual Attitudes and Lifestyles (Natsal-3). Lancet. 2013;382:1807-1816.

47. Holing EV. Preconception care of women with diabetes: the unrevealed obstacles. J Matern Fetal Neonatal Med. 2000;9:10-13.

48. Griffiths $F$, Lowe $P$, Boardman $F$, et al. Becoming pregnant: exploring the perspectives of women living with diabetes. Br J Gen Pract. 2008;58(548):184-190.

49. Bachrach CA, Newcomer S. Intended pregnancies and unintended pregnancies: distinct categories or opposite ends of a continuum? Fam Plann Perspect. 1999;31(5):251-252.

50. Barrett G, Wellings K. What is a 'planned' pregnancy? Empirical data from a British study. Soc Sci Med. 2002;55(4):545-557.

51. MoosMK. Preconception care: everywoman, every time.AWHONN Lifelines. 2006;10(4):332-334.

52. Shannon GD, Alberg C, Nacul L, et al. Preconception healthcare delivery at a population level: construction of public health models of preconception care. Matern Child Health J. 2014;18(6):1512-1531.

53. Hillemeier MM, Weisman CS, Chase GA, et al. Women's preconceptional health and use of health services: implications for preconception care. Health Serv Res. 2008;43(1 Pt 1):54-75.

54. Hogan VK, Culhane JF, Crews KJ, et al. The impact of social disadvantage on preconception health, illness, and wellbeing: an intersectional analysis. Am J Health Promot. 2013;27: eS32-eS42.

55. Handler A, Rankin KM, Peacock N, et al. The implementation of interconception care in two community health settings: lessons learned. Am J Health Promot. 2013;27:eS21eS31.

56. Finocchario-Kessler S, Mabachi N, Dariotis JK, et al. We weren't using condoms because we were trying to conceive": the need for reproductive counseling for HIV-positive women in clinical care. AIDS Patient Care STDS. 2012;26:700-707.

57. Bronstein JM, Felix HC, Bursac Z, et al. Providing general and preconception health care to low income women in family planning settings: perception of providers and clients. Matern Child Health J. 2012;16(2):346-354.

58. Holing EV, Beyer CS, Brown ZA, et al.Why don't women with diabetes plan their pregnancies? Diabetes Care. 1998;21:889-895.

59. Frayne DJ, Verbiest S, Chelmow D, et al. Health care system measures to advance preconception wellness: consensus recommendations of the Clinical Workgroup of the National Preconception Health and Health Care Initiative. Obstet Gynecol. 2016;127(5):863-872.

60. Rosenbaum S. Women and health insurance: implications for financing preconception health. Womens Health Issues. 2008; 18(6):S26-S35.

\section{TABLES AND FIGURE}

TABLE 1

Search Syntax

DOMAIN: preconception, pre-conception, pre-pregnancy, pre-prenatal, periconception, interconception I care, advice, consult, counseling assessment, intervention, treatment, referral, screening, diagnosis, prevention, health promotion, risk assessment.

DETERMINANT: determinant, variable, factor, aspect, motives, motivation, facilitator, barrier, constraint, benefit, success, fail, advantage, disadvantage, condition, term, decision, reason, choice, attitude, emotion, perception, perspective, intention, subjective, belief, wish, fear, value, norm, need, influence, awareness, ethics, moral, importance, ability, access, inform, knowledge, skill, self-efficacy. OUTCOME: use, usage, utilization, reach, receipt, uptake, attend, visit, participation, acceptance. 
Poels, M., Koster M.P.H., Boeije, H.R., Franx, A., Stel, H.F. Why do women not use preconception care? A systematic review on barriers and facilitators. Obstetrical and Gynecological Survey: 2016, 71(10), 603-612
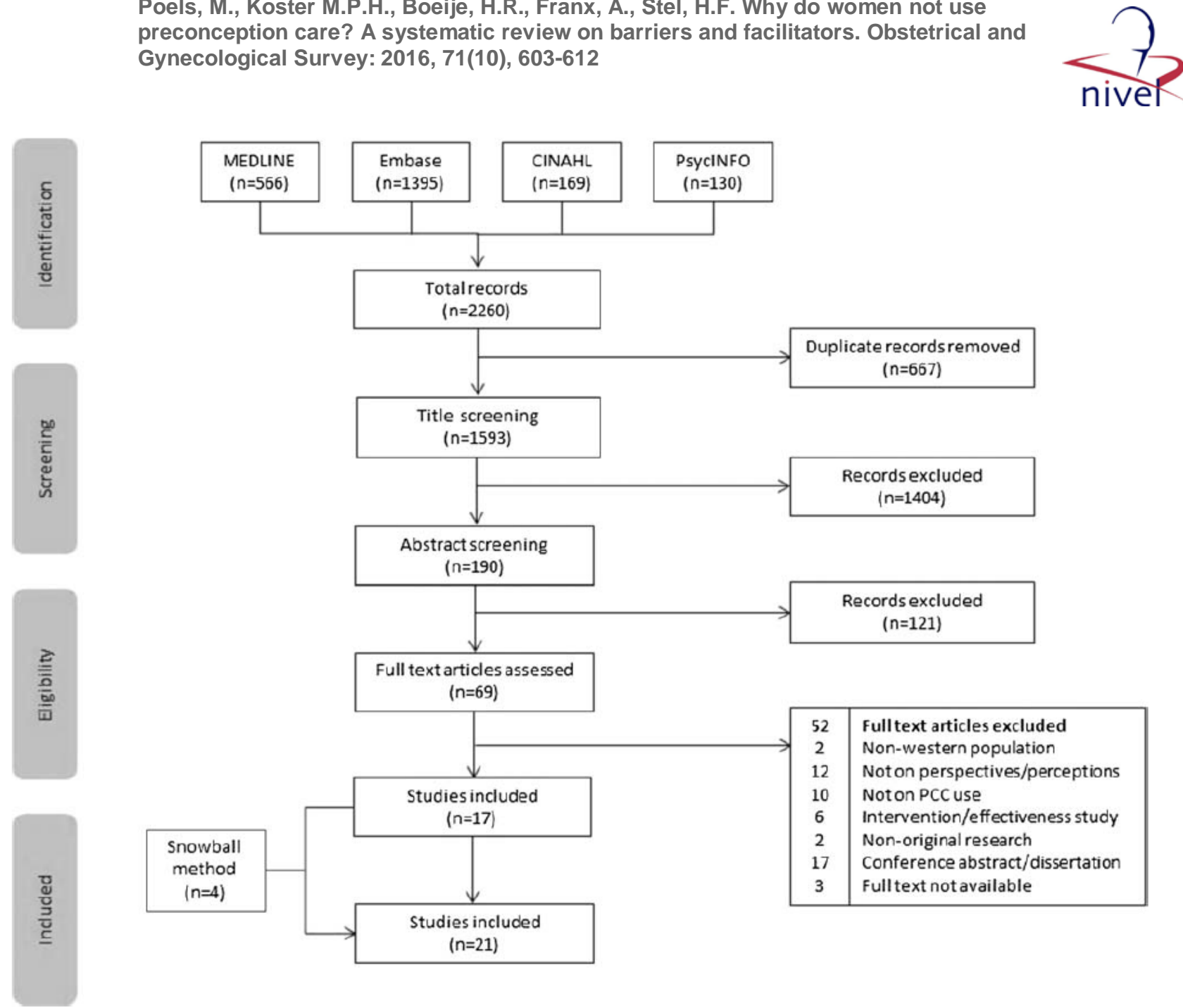

FIG. 1. Flow chart of article selection process.

TABLE 2

Characteristics of the 21 Included Studies

\begin{tabular}{|c|c|c|c|c|c|c|}
\hline Study & Year & Country & Design & Data Collection & $\mathrm{N}$ & Sample \\
\hline Canady et $a^{23}$ & 2008 & USA & Qualitative & Focus groups & 168 & African-American \\
\hline Charron-Prochownik et al ${ }^{24}$ & 2001 & USA & Quantitative & Questionnaires & 80 & DM 1 \\
\hline Charron-Prochownik et al ${ }^{25}$ & 2006 & USA & Qualitative & Open-ended questionnaire & 80 & DM 1 \\
\hline Coonrod et $\mathrm{al}^{26}$ & 2009 & USA & Quantitative & Questionnaires & 305 & Mexican-American \\
\hline de Jong-Potjer et al ${ }^{27}$ & 2003 & the Netherlands & Quantitative & Questionnaires & 1206 & \\
\hline Elsinga et $\mathrm{al}^{28}$ & 2006 & the Netherlands & Quantitative & Questionnaires & 14915 & \\
\hline Frey and Files ${ }^{29}$ & 2006 & USA & Quantitative & Questionnaires & 499 & \\
\hline Hosli et $\mathrm{al}^{5}$ & 2008 & the Netherlands & Qualitative & Semi-structured interviews & 11 & \\
\hline Janz et $\mathrm{al}^{30}$ & 1995 & USA & Quantitative & Questionnaires & 154 & $\mathrm{DM}$ \\
\hline Mazza and Chapman ${ }^{8}$ & 2010 & Australia & Qualitative & Focus groups & 17 & \\
\hline Mitchell et al ${ }^{31}$ & 2012 & USA & Quantitative & Questionnaires & 2736 & \\
\hline Murphy et $\mathrm{al}^{32}$ & 2010 & UK & Qualitative & Semi-structured interviews & 29 & $\mathrm{DM} 1+2$ \\
\hline O'Higgins et $\mathrm{al}^{33}$ & 2014 & Ireland & Qualitative & Participative research & 14 & $\mathrm{DM} 1+2$ \\
\hline Spence et al ${ }^{34}$ & 2010 & UK & Qualitative & Focus groups & 24 & $\mathrm{DM} 1+2$ \\
\hline Squiers et $\mathrm{al}^{35}$ & 2013 & USA & Qualitative & Focus groups & 65 & \\
\hline Temel et $\mathrm{al}^{36}$ & 2013 & the Netherlands & Quantitative & Questionnaires & 631 & \\
\hline Tuomainen et al ${ }^{37}$ & 2013 & UK & Qualitative & Focus groups / semi-structured interviews & $41 / 19$ & \\
\hline Van der Zee et al ${ }^{\beta 8}$ & 2013 & the Netherlands & Qualitative & Semi-structured interviews & 16 & \\
\hline Vause et $\mathrm{al}^{39}$ & 2009 & Canada & Quantitative & Questionnaires & 400 & Infertility patients \\
\hline Wallace and Hurwitz ${ }^{40}$ & 1998 & UK & Quantitative & Questionnaires & 811 & \\
\hline Zhu et $\mathrm{al}^{41}$ & 2012 & Australia & Quantitative & Questionnaires & 51 & $\mathrm{DM} 1+2$ \\
\hline
\end{tabular}


Poels, M., Koster M.P.H., Boeije, H.R., Franx, A., Stel, H.F. Why do women not use preconception care? A systematic review on barriers and facilitators. Obstetrical and Gynecological Survey: 2016, 71(10), 603-612

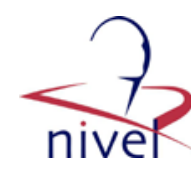

TABLE 3

Themes and Topics in the Included Studies

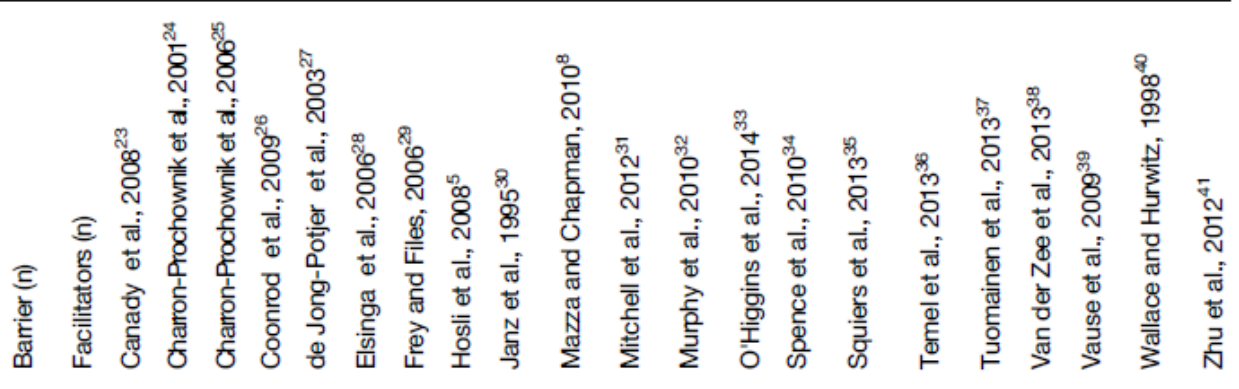

\begin{tabular}{|c|c|c|c|c|c|c|c|c|c|c|c|c|c|c|c|c|c|c|c|c|c|}
\hline 1. Preconditions & & & & & & & & & & & & & & & & & & & & & \\
\hline Interest & 1 & 6 & & + & + & + & + & + & & & & & & & & & & & + & & - \\
\hline PCC Awareness & 8 & 2 & - & +- & - & & & & & & + & - & - & & - & & - & & & & - \\
\hline $\begin{array}{l}\text { Pregnancy planning } \\
\text { 2. Emotions and beliefs }\end{array}$ & 8 & 1 & - & & & - & - & & & & + & - & & - & & & - & - & & & - \\
\hline Wish for secrecy & 2 & 0 & & & & & & & & & & & & & & & - & - & & & \\
\hline Wish for normality & 2 & 1 & & & & & & & & & & - & + & & & & & - & & & \\
\hline Anxiety \& fears & 5 & 0 & & & & & & & & & & - & - & - & & - & - & & & & \\
\hline Benefits & 2 & 10 & & + & + & & & & + & + & + & + & + & & $+/-$ & - & + & + & & & \\
\hline 3. Perceived need & & & & & & & & & & & & & & & & & & & & & \\
\hline Perceived relevance \& importance & 6 & 3 & & & & & & + & - & & & + & & & & - & - & - & + & - & \\
\hline Perceived risk status & 7 & 0 & - & & & - & & & - & & - & & - & & & & - & - & & & \\
\hline Medicalization of conception & 3 & 1 & - & & & & & & & & - & - & & & & & & + & & & \\
\hline $\begin{array}{l}\text { Fertility concerns } \\
\text { 4. Experience }\end{array}$ & 1 & 4 & + & & & & & & + & & & - & & & & & + & + & & & \\
\hline Sufficient knowledge & 5 & 0 & & & & & - & & - & & - & & & & & & & - & & & - \\
\hline $\begin{array}{l}\text { Pregnancy experiences } \\
5 \text {. Social structure }\end{array}$ & 8 & 2 & + & & & & & & - & & - & $+1-$ & & & & - & - & - & & - & - \\
\hline Social system & 4 & 5 & & & & & & & & + & & - & + & & + & $+/-$ & - & - & & & \\
\hline $\begin{array}{l}\text { Religion } \\
6 . \text { Accessibility }\end{array}$ & 2 & 0 & & & & & & & & & & & & & & - & - & & & & \\
\hline Distance/rurality & 3 & 0 & & & & & & & & & - & - & & & & & & & & & - \\
\hline Cost & 3 & 1 & & & & & & & & & - & - & & + & - & & & & & & \\
\hline Time and effort & 4 & 0 & & & & & & & & & & & - & & & - & - & & & & - \\
\hline $\begin{array}{l}\text { Availability } \\
\text { 7. Provider characteristics }\end{array}$ & 6 & 7 & & & & + & + & - & & + & $+/-$ & - & - & - & - & & + & & & $+1-$ & \\
\hline Female provider & 0 & 2 & & & & & & & & & & & & + & & & + & & & & \\
\hline Provider attitudes & 2 & 3 & & & & & & & & + & & & + & - & & & - & + & & & \\
\hline Communication issues & 3 & 0 & & & & & & & & & & - & & - & & & - & & & & \\
\hline Experiences with health services & 3 & 3 & & & & & & & & & - & $+/-$ & + & - & & & + & & & & \\
\hline
\end{tabular}

Classified into barriers (-) and facilitators (+) for the use of preconception care. 